\title{
Gender differences in response to a school-based mindfulness training intervention for early adolescents
}

\author{
Yoona Kang ${ }^{\mathrm{a}, *}$, Hadley Rahrig ${ }^{\mathrm{b}}$, Kristina Eichel $^{\mathrm{f}}$, Halsey F. Niles ${ }^{\mathrm{b}, \mathrm{c}}$, Tomas Rocha ${ }^{\mathrm{d}}$, \\ Nathaniel E. Lepp ${ }^{\mathrm{b}}$, Jonathan Gold ${ }^{\mathrm{b}, \mathrm{e}}$, Willoughby B. Britton ${ }^{\mathrm{b}, \mathrm{f}, * *}$
}

a Annenberg School for Communication, University of Pennsylvania, United States

${ }^{\mathrm{b}}$ Brown University Contemplative Studies Initiative, United States

${ }^{\mathrm{c}}$ Benson-Henry Institute for Mind Body Medicine, Massachusetts General Hospital, United States

${ }^{\mathrm{d}}$ Philasophy and Education, Columbia University, United States

e Moses Brown School, United States

${ }^{\mathrm{f}}$ Department of Psychiatry and Human Behavior, Brown University Medical School, United States

\section{A R T I C L E I N F O}

Action Editor: Andy Roach

Keywords:

Mindfulness

Meditation

Gender difference

Early adolescence

Emotions

Affect

\begin{abstract}
A B S T R A C T
Mindfulness training has been used to improve emotional wellbeing in early adolescents. However, little is known about treatment outcome moderators, or individual differences that may differentially impact responses to treatment. The current study focused on gender as a potential moderator for affective outcomes in response to school-based mindfulness training. Sixth grade students $(N=100)$ were randomly assigned to either the six weeks of mindfulness meditation or the active control group as part of a history class curriculum. Participants in the mindfulness meditation group completed short mindfulness meditation sessions four to five times per week, in addition to didactic instruction (Asian history). The control group received matched experiential activity in addition to didactic instruction (African history) from the same teacher with no meditation component. Self-reported measures of emotional wellbeing/affect, mindfulness, and self-compassion were obtained at pre and post intervention. Meditators reported greater improvement in emotional wellbeing compared to those in the control group. Importantly, gender differences were detected, such that female meditators reported greater increases in positive affect compared to females in the control group, whereas male meditators and control males displayed equivalent gains. Uniquely among females but not males, increases in self-reported selfcompassion were associated with improvements in affect. These findings support the efficacy of school-based mindfulness interventions, and interventions tailored to accommodate distinct developmental needs of female and male adolescents.
\end{abstract}

\section{Introduction}

Early adolescence presents unique developmental challenges and opportunities for implementing mental health intervention strategies. Early symptoms of emotional disturbance, such as depression or context-inappropriate behaviors or feelings (Code of Federal Regulations, Title 34, §300.8(c)(4)(ii), 2004) tend to emerge during early adolescence (Paus, Keshavan, \& Giedd, 2008) with

\footnotetext{
* Correspondence to: Y. Kang, Annenberg School for Communication, University of Pennsylvania, 3620 Walnut Street, PA 19104, United States.

** Correspondence to: W.B. Britton, Department of Psychiatry and Human Behavior, Warren Alpert Medical School at Brown University, 185 Brown Street, Providence, RI 02906, United States.

E-mail addresses: yoona.kang@asc.upenn.edu (Y. Kang), willoughby_britton@brown.edu (W.B. Britton).
} 
the prevalence rate of $11 \%$ to $50 \%$ of school-age children experiencing emotional problems severe enough to warrant the use of mental health services (Carter et al., 2010; Kessler et al., 2012; Romano, Tremblay, Vitaro, Zoccolillo, \& Pagani, 2001; U.S. Department of Health and Human Services, and Centers for Disease Control and Prevention, 2013). Given the prevalence of pathology and wide need for prevention, development of cost-effective and generalizable interventions that aim to improve emotional wellbeing of adolescents is critical. One emerging strategy that has shown promising effects among the adolescent populations is mindfulness training (Biegel, Brown, Shapiro, \& Schubert, 2009; Bögels, Hoogstad, Dun, Schutter, \& Restifo, 2008; Broderick \& Metz, 2009; Napoli, Krech, \& Holley, 2005; Saltzman \& Goldin, 2008; Schonert-Reichl \& Lawlor, 2010; for a review, see Burke, 2010). However, less is known about moderators of treatment outcomes or factors that influence treatment efficacy that are necessary to inform successful development of evidence-based intervention strategies (Ospina et al., 2007). The current study addressed gender, a critically relevant risk factor for emotional wellbeing/affect among adolescents (for meta-analyses, see Else-Quest, Hyde, Goldsmith, \& Van Hulle, 2006; Hofmann, Sawyer, Witt, \& Oh, 2010), as a potential treatment outcome moderator for mindfulness intervention success among early adolescents.

\subsection{Mindfulness training in school}

Mindfulness training aims to cultivate mindful awareness with nonjudgmental approaches to thoughts, sensations, and feelings, and greater compassion toward one's thoughts and actions (Kabat-Zinn, 1990). Mindfulness training was previously shown to increase self-reported mindfulness (Chambers, Lo, \& Allen, 2008; Zeidan, Johnson, Diamond, David, \& Goolkasian, 2010) and selfcompassion (Birnie, Speca, \& Carlson, 2010; Neff, 2003), and positive affect was associated with increases in mindfulness (Baer, 2003) and self-compassion (Hollis-Walker \& Colosimo, 2011; Van Dam, Sheppard, Forsyth, \& Earleywine, 2011). Therefore, improvements in mindfulness and self-compassion in meditators may predict enhanced affective wellbeing.

Mindfulness training aims to cultivate moment-to-moment non-elaborative attention to and awareness of external and internal events, such as thoughts, emotions and body sensations (Kabat-Zinn, 1990). In practice, individuals maintain awareness of and attention to the present moment, whenever mind wanders, gently but firmly bring back the focus of attention to the initial target object. The goal of such practice is to train the mind to be stable and disengage from habitual mental processes, such as emotional reactivity (Kang, Gruber, \& Gray, 2013, 2014). Mindful attention may allow individuals to identify secondary elaboration of thought processes at the moment they enter the mind. For example, when a student fails an exam, her mind may generate condemnatory selfevaluations (e.g., "I am a failure."). Mindful attitude may either prevent such secondary evaluations from occurring, or help individuals to embrace already occurred evaluative thoughts as they are, without suppression or distortion (e.g., "I am feeling as though I am a failure.”). Maintaining a subtle distance from mental experiences and observing thoughts as mental events that do not necessarily reflect facts of reality, or de-centering through mindful attention (Segal, Williams, \& Teasdale, 2002), can in turn lead to healthy coping strategies to social and academic challenges unique to school environments.

Mindful skills may be particularly beneficial in the midst of increasing demands and challenges students face in their academic and social life. Currently, an increasing number of youths are experiencing clinical disorders and stress-related behavioral problems (e.g., Card \& Hodges, 2008; Currie et al., 2002; Lohaus \& Ball, 2006): It is estimated that 22.2\% of the youths in United States currently have or will have a severe mental disorder (Merikangas et al., 2010), with affect-related disorders such as anxiety and depression being among the most prevalent diagnoses (World Health Organization, 2002). Thus, considering the mental health of students is increasingly imperative to successful formal education, and the vital function of contemporary schools should include not only propagating knowledge, but also cultivating cognitive and affective skills to prevent psychological disorders and adaptively manage social and academic stressors.

School-based mindfulness training can be a powerful addition to existing school programs and can effectively function to meet students' psychological needs. First, mindfulness practice explicitly aims to enhance positive qualities of mind including self-discipline, emotion awareness and regulation, prosocial orientation such as compassion and empathy, and ethical decision making (e.g., Zenner, HerrnlebenKurz, \& Walach, 2014). These qualities might in turn help students to adaptively respond to increasing challenges and flourish in stressful environments (e.g., Shapiro, Brown, \& Astin, 2008). Second, school is the primary foundation of most children's social life outside family, and what they have learned through mindfulness training can be directly applied among their peers. Continuous feedback loops can motivate students and provide an ideal ground to monitor their progress. Third, the preventative nature of mindfulness training may provide additional benefits to nonclinical groups before problematic behaviors reach a clinical severity (e.g., Britton et al., 2014). It can also help avoid social stigma associated with traditional clinical treatment programs for clinical groups. Fourth, mindfulness-based programs are often administered in groups, akin to classroom settings, and with standardized intervention modules at a relatively low cost (Weare \& Nind, 2011). Mindfulness training may be especially effective for the schools in low income and underserved communities, where the need for general and preventative mental health resources is greatest (Mendelson et al., 2010). These unique features collectively position mindfulness training feasible for school-based group interventions.

For these reasons, mindfulness is especially suitable for integration into school psychology practice (Felver, Doerner, Jones, Kaye, \& Merrell, 2013); however, mindfulness research is yet to be centrally established in school psychology. Theories and practice available in mindfulness can offer new and effective school-based interventions to help maintain and enhance affective health of students. Mindfulness intervention could be implemented by school psychologists with foundational training in mindfulness intervention via classroom-based small group interventions, and school psychology programs can prepare clinicians who can provide mindfulness-based consultative services in school. Given their specific training and major roles in addressing mental health needs of adolescents, school psychologists can provide insights into the mindfulness-based intervention research for children, and more generally, the development of preventative interventions that focus on using inherent individual strengths of the child. 


\subsection{Mindfulness training and emotional wellbeing among early adolescents}

Given the gender difference in affect and affect processing, different genders may respond to mindfulness interventions through potentially divergent affect-related mechanisms. Specifically, affect-related gender differences may lead not only to divergent outcomes but also through different pathways, that is, female and male participants may both show improvements in affect outcomes but through distinctive mechanisms. Consistent with this idea, improvements in affective health in female adults as a function of mindfulness training was associated with increases in self-compassion, whereas for male counterparts, self-compassion was not associated with changes in affect (Rojiani, Santoyo, Rahrig, Roth, \& Britton, 2017). Because of the greater risk and need for prevention/treatment of affective disturbance among female adolescents compared to males, we focused on the mechanisms that may explain positive affect changes in females. Changes in self-compassion and mindfulness as a function of mindfulness training were examined, and whether they differ in predicting outcomes by gender. In particular, we tested whether more affective (vs. cognitive) pathway through increases in compassion (vs. mindfulness) may lead to greater changes in emotional wellbeing among females.

Mindfulness research among early adolescents is still in its infancy and more extensive studies are warranted to test its suitability and efficacy in this population; however, initial findings seem promising. Preliminary evidence supports general benefits of mindfulness training among youths across a wide range of domains including academic performance (Sibinga et al., 2011), social skills (Beauchemin, Hutchins, \& Patterson, 2008), aggressive behavior (Singh et al., 2011; Singh et al., 2011), and sleep quality (Bootzin \& Stevens, 2005; Britton et al., 2010), among various other outcomes (for a review, see Burke, 2010; c.f., Maynard, Solis, Miller, \& Brendel, 2017).

In our previous report (the same sample as in the current study), mindfulness training improved emotional wellbeing among early adolescents (Britton et al., 2014). Other preliminary evidence supports overall efficacy of mindfulness intervention on emotional wellbeing in youths (for reviews, see Felver, Celis-de Hoyos, Tezanos, \& Singh, 2016; Greenberg \& Harris, 2012): Among K-12 grades, mindfulness training was associated with decreased negative affect and increased positive affect (Broderick \& Metz, 2009), decreased emotional reactivity (Saltzman \& Goldin, 2008) and emotional discomfort (Sibinga et al., 2011), improved teacher-reported socioemotional competence (Schonert-Reichl \& Lawlor, 2010), improved self-reported emotion regulation/stress coping (Broderick \& Metz, 2009), increased subjective happiness (Bögels et al., 2008), and reduced symptoms of affect disorders such as anxiety (Biegel et al., 2009; Napoli et al., 2005), depression (Biegel et al., 2009; Liehr \& Diaz, 2010; Tan \& Martin, 2012), and rumination (Mendelson et al., 2010). Finally, four meta-analyses results (Black, Milam, \& Sussman, 2009; Kallapiran, Koo, Kirubakaran, \& Hancock, 2015; Zenner et al., 2014; Zoogman, Goldberg, Hoyt, \& Miller, 2015) support that mindfulness training programs may be promising interventions designed to benefit affective health of children and early adolescents. However, several studies also report null or mixed effects (for a review, see Maynard et al., 2017), highlighting the complexity of mindfulness as an intervention strategy and the importance of examining potential moderators of the outcomes.

We propose that a critical next step is to examine individual difference variables among youths that may lead to divergent suitability and efficacy outcomes. Specifically, we focus on gender as a potential variable that may moderate the effects of meditation training (e.g., Desbordes et al., 2012). Data from our own lab (Rojiani et al., 2017) and others (de Vibe et al., 2013) showed gender at as an outcome moderator in adults (for a review, see Katz \& Toner, 2013), such that female adults were generally shown to respond to meditation intervention favorably whereas male counterparts did not. In youth populations, it is still unknown if gender also serves as a moderator. Examining potential gender effects is especially important given the prevalence of gender difference in affective disturbances and treatment outcomes among adolescents (Table 1), and can help refine and enhance existing programs and critically inform future development of school-based mindfulness programs. Therefore, we re-analyzed our pre-existing dataset (Britton et al., 2014) to test whether gender served as a moderator in youths as well.

\subsection{Gender differences in affective disturbance and treatments}

In early childhood, no apparent gender difference exists in most affect-related disorders such as depression (Brooks-Gunn \& Petersen, 1991; Nolen-Hoeksema, 1987; Rutter, Izard, \& Read, 1986), and anxiety disorders (Lewinsohn, Gotlib, Lewinsohn, Seeley, \& Allen, 1998). Around the onset of puberty, however, a marked gender difference emerges such that by late adolescence, females are about twice as likely to experience symptoms of depression (for reviews, see McGrath, Keita, Strickland, \& Russo, 1990; NolenHoeksema, 1987), and anxiety (Lewinsohn et al., 1998) than their male counterparts.

Researchers argue that this gender-moderated emergence of affective illness is due to the increased affect-related risk factors among females compared to males during early adolescence (e.g., Nolen-Hoeksema \& Girgus, 1994). Such risk factors that unfavorably impact females include negative affectivity (Lewinsohn et al., 1998), which describes increased sensitivity to negative stimuli that leads to a broad range of negative moods (Clark, Watson, \& Mineka, 1994), and maladaptive coping strategies that lead to negative affect (e.g., self-criticism, rumination; Nolen-Hoeksema \& Girgus, 1994). As summarized in Table 1, several studies have found gender-based differences in affective disorder and intervention outcomes. Given the consistent evidence on gender-based differences in affect processing, interventions that aim to modify affect and affect-related coping strategies may differentially impact males and females during early adolescence (Table 1). Consistent with this prediction, cognitive behavioral therapy (CBT) may lead to diverging coping styles among male and female adolescents, such that females endorsed greater use of affective support seeking as a coping strategy compared to males (Mendlowitz et al., 1999). Mindfulness training specifically targets risk factors that are unique to female adolescents such as positive affectivity (Anderson, Lau, Segal, \& Bishop, 2007; Nyklíček \& Kuijpers, 2008; Ortner, Kilner, \& Zelazo, 2007) and adaptive coping strategies (Birnie et al., 2010). Therefore, females may demonstrate greater improvements in their emotional wellbeing as a result of mindfulness training compared to their male counterparts. 
Table 1

Studies on gender-based differences in affective disorder and intervention outcomes.

\begin{tabular}{|c|c|c|c|}
\hline Citations & $\begin{array}{l}\text { Sample size } \\
\text { (females) }\end{array}$ & $\begin{array}{l}\text { Mean age } \\
\text { (range) }\end{array}$ & Key outcomes \\
\hline Briere, Rohde, Stice, \& Morizot, 2016 & $631(365)$ & $15.5(13-19)$ & $\begin{array}{l}\text { A Cognitive Behavioral (CB) intervention was administered to adolescents with } \\
\text { depression. Girls were more likely to experience a chronic course of depression } \\
\text { and were less likely to benefit from CB. }\end{array}$ \\
\hline $\begin{array}{l}\text { Bender, Reinholdt-Dunne, Esbjørn, \& } \\
\quad \text { Pons, } 2012\end{array}$ & $544(298)$ & $12.24(9-16)$ & $\begin{array}{l}\text { Girls experience more difficulties in emotion regulation, and compared to boys, } \\
\text { are more likely to experience anxiety due to difficulties in emotion regulation. }\end{array}$ \\
\hline Calvete \& Cardeñoso, 2005 & $856(491)$ & $15.92(14-17)$ & $\begin{array}{l}\text { Gender differences in depression were mediated by negative self-focused } \\
\text { cognitions and the need for approval and success. This pattern was more } \\
\text { prevalent in younger adolescents relative to older adolescents. }\end{array}$ \\
\hline Deardorff et al., 2007 & $106(55)$ & $10.25(9.5-11)$ & $\begin{array}{l}\text { This study investigates the effects of gender and puberty on symptoms of social } \\
\text { anxiety. Advanced puberty is associated with increased social anxiety symptoms } \\
\text { in girls but not in boys. }\end{array}$ \\
\hline De Boo \& Spiering, 2010 & 404 (219) & $10.7(8-12)$ & $\begin{array}{l}\text { Gender differences in vulnerability to depression are measurable in pre- } \\
\text { adolescence and are related to mood and emotional coping strategies. }\end{array}$ \\
\hline $\begin{array}{l}\text { Essau, Lewinsohn, Seeley, \& } \\
\quad \text { Sasagawa, } 2010\end{array}$ & $773(460)$ & $16.6(14-17)$ & $\begin{array}{l}\text { Lower onset age predicted greater likelihood of developing a chronic course of } \\
\text { depression (more episodes) in girls but not in boys. Into adulthood girls } \\
\text { experienced longer and more frequent episodes of depression. }\end{array}$ \\
\hline Graham \& Weems, 2015 & 225 (124) & $12.28(6-17)$ & $\begin{array}{l}\text { Parental anxiety sensitivity and parenting style affect boys and girls } \\
\text { differentially. Parental anxiety is predictive of anxiety in girls, but is negatively } \\
\text { associated with anxiety in boys. }\end{array}$ \\
\hline $\begin{array}{l}\text { Hankin, Mermelstein, \& Roesch, } \\
2007\end{array}$ & $538(293)$ & $14.9(13-18)$ & $\begin{array}{l}\text { Girls reported greater levels of depressive symptoms and girls experienced more } \\
\text { stressors compared to boys, particularly in the interpersonal domain. }\end{array}$ \\
\hline $\begin{array}{l}\text { Mezulis, Funasaki, Charbonneau, \& } \\
\text { Hyde, } 2010\end{array}$ & $366(185)$ & $\begin{array}{l}11.2 \text { and } \\
15.2(11-15)\end{array}$ & $\begin{array}{l}\text { Cognitive vulnerability and life stress differentially interact with depression } \\
\text { trajectories, which in turn are moderated by gender. }\end{array}$ \\
\hline Muris, Mayer, \& Schubert, 2010 & 209 (106) & $11.07(10-13)$ & $\begin{array}{l}\text { A feminine gender role is positively associated with fear and anxiety in children, } \\
\text { indicating that gender role orientation apart from physiological sex influences } \\
\text { affective patterns in children. }\end{array}$ \\
\hline $\begin{array}{l}\text { Walsh, Stewart, McLaughlin, \& } \\
\quad \text { Comeau, } 2004\end{array}$ & $1698(821)$ & $14.3^{\mathrm{a}}$ & $\begin{array}{l}\text { Girls score higher on global measures of anxiety sensitivity. Factors contributing } \\
\text { to anxiety differ between girls and boys, with girls demonstrating more } \\
\text { physically-related concerns relative to psychological or social concerns. }\end{array}$ \\
\hline
\end{tabular}

${ }^{\text {a }}$ Information on age range not available.

\subsection{The current study and research questions}

Consistent with previous findings on the psychological benefits of mindfulness training among youths (Black et al., 2009; Shapiro, Astin, Bishop, \& Cordova, 2005), we predicted and previously reported using the same sample, that mindfulness training can increase emotional wellbeing among early adolescents (Britton et al., 2014). The current study further examined gender as a potential moderator for affective outcomes in response to school-based mindfulness training among early adolescents.

Q1. Given the risk factors that place female students at greater disadvantage in terms of affect and affect-related coping styles, and based on the evidence of mindfulness training improving these outcomes, we tested whether mindfulness training would bring greater benefits in affective symptoms for female than for male students.

Q2. We examined whether increases in mindfulness and self-compassion would be associated with improvements of affect outcomes, and tested potential gender difference in these relations.

\section{Method}

\subsection{Participants}

One hundred fourteen sixth graders were recruited who were nearing the age when the gender difference in affective health tends to emerge and the need for preventative mental health resources becomes salient especially for female students. The intervention was offered as a part of pre-existing curriculum (i.e., history classes) in a private middle school in Providence, Rhode Island, as approved by the school board members and in consultation with the school psychologists in order to ensure the students' educational experience. All male students identified as boys and female students as girls in this study. An initial sample of 101 students agreed to participate. Across the period of two years the study was conducted (from October 2007 to April 2009), one participant did not complete the study, and the final sample consisted of 100 participants ( 46 females, mean age $=11.79$ years, $S D=0.41$, Table 2 ). The study was approved by The Brown University Institutional Review Board and the Moses Brown School, and all students and their parents completed informed assent and consent procedures.

\subsection{Procedure}

The study investigated four different classrooms, two each in two consecutive fall semesters. In both years, as a part of the current 
Table 2

Participant demographics and baseline characteristics.

\begin{tabular}{llll}
\hline & Mindfulness meditation $(n=52)$ & Active control $(n=48)$ & Statistic \\
\hline Demographic & & & \\
Age (yrs) & $11.73(0.45)$ & $41.85(0.36)$ & \\
Female (\%) & $44 \%=2.30$ & \\
Baseline characteristics & & & \\
Global affect (STAI-C) & $453.90(222.56)$ & $425.85(239.40)$ & \\
Positive affect (STAI-C) & $491.17(117.76)$ & $511.06(114.35)$ & \\
Mindfulness (CAMS-R) & $33.00(5.58)$ & $32.94(5.55)$ & $F=0.14$ \\
Self-compassion (SCS) & $3.36(0.58)$ & $3.16(0.64)$ & $F=0.01$ \\
& & & $F=2.71$ \\
\hline
\end{tabular}

Note. Data on race/ethnicity and socioeconomic status/free and reduced price lunches was not collected. CAMS- $\mathrm{R}=$ Cognitive and Affective Mindfulness Scale-Revised; SCS = Self-Compassion Scale; STAI-C = Spielberger Anxiety Inventory-Child version. Mean values are displayed with standard deviations in parentheses where applicable.

study and in accordance with school policy, all sixth-grade students are assigned to one of two classrooms by a committee of educators where each classroom is matched in terms of aptitude, learning style, maturity, social characteristics, and gender. In a given year, one of these two classrooms was randomly assigned to the mindfulness meditation group, and the other to the active control group via a coin-flip. Upon completion of the six-week intervention course, group assignment was reversed in spring semesters such that all participants received both meditation and active control modules. The current study only reports data from the initial group assignment of the four classrooms (two in initial meditation, and two in initial control groups) during fall semesters across the two years.

All participants provided informed assent and parental consent prior to random assignment to either the mindfulness meditation or the control group. The mindfulness meditation and active control intervention modules were offered in an Asian history and African history class, respectively. Participants completed a battery of surveys before (pretest) and after (posttest) the six-week intervention period. All tests were administered in classrooms during regular school hours. All experimenters who worked with participants and the participants themselves were blind to the study questions throughout the study, and the researchers who coded and processed the data were blind to the group assignment. Adverse events were monitored through written feedback after each meditation session, and through questionnaire "critical items" related to suicidal ideation and self-harm. Endorsement of any critical items resulted in evaluation, treatment, and continued monitoring by the school psychologist.

\subsection{Interventions}

\subsubsection{Mindfulness meditation group}

The six-week mindfulness meditation intervention was developed based on the Integrative Contemplative Pedagogy method (ICP; Roth, 2014) that integrates traditional third person knowledge-based learning (lecture) with first person experiential learning (meditation). The mindfulness meditation modules were taught as a part of an Asian history class. For example, the third person class module consisted of lectures on Asian civilizations, whereas the first person module involved experiencing three different meditation techniques. The main mindfulness meditation techniques included (1) breath awareness/breath counting, (2) awareness of thoughts, feelings, and sensations, and (3) body sweeps. The breath awareness/breath counting module was taught for the first two weeks, followed by one week of awareness of thoughts, feelings, and sensations, and one week of body sweeps. During the final two weeks, students were free to choose from the three techniques for their practice.

Four to five times a week, participants were guided through a short silent meditation session at the beginning of each class. The minutes of meditation ranged from initial $3 \mathrm{~min} /$ class to incrementally increased $12 \mathrm{~min} /$ class by the end of sixth week (5 min/class on average). Throughout the meditation practice, students were instructed to sit with a straight posture on their desk chairs with their hands folded in their laps and their eyes either open or closed as they wished.

Two history teachers led the meditation following identical practice instruction transcripts. One teacher completed Roth's (2014) ICP training and had five years of prior meditation experience; the second teacher had completed an eight-week Mindfulness-Based Stress Reduction course (Kabat-Zinn, 1990) provided by the research team prior to teaching.

\subsubsection{Control group}

The six-week active control intervention was matched to the mindfulness intervention to fulfill the ICP approach for which didactic content was matched to experiential content. Specifically, it included a third person knowledge-based learning of African history taught by the same teachers as in the meditation group. To match the meditation intervention's first person experiential learning component, the control intervention also included experiential and novel activities relevant to the lecture material (i.e., construction of a life-sized model of an Egyptian sarcophagus). 


\subsection{Measures}

\subsubsection{Affect/emotional wellbeing}

Affect was the primary outcome measure of the current study, and changes in participants' affect or emotional wellbeing were measured by a modified version of the 20-item Spielberger Anxiety Inventory-Child version (STAI-C; Spielberger, Gorsuch, \& Lushene, 1970). Originally intended to assess anxiety, the STAI is now commonly used to assess a broad range of emotional health (Bieling, Antony, \& Swinson, 1998; Caci et al., 2003; Grös, Antony, Simms, \& McCabe, 2007). STAI-C includes ten negative (upset, nervous, jittery, scared, worried, frightened, troubled, bothered, terrified, mixed-up) and ten positive (calm, pleasant, rested, relaxed, satisfied, happy, sure, good, nice, cheerful) affect items. To increase sensitivity of the scale and enhance the ease of use for children (Bringuier et al., 2009; Foster \& Park, 2012), the original STAI-C's 3-choice format was replaced by visual analog scales that allow examination of affect along a continuous spectrum, ranging from 0 (e.g., not calm, not upset) to 75 (e.g., very calm, very upset). A global affect disturbance score that represents emotional disturbance was created by summing all negative emotion items and reverse-coded positive emotion items, with scores range from 0 to 1500 .

In addition to the STAI global affect disturbance score, valence-specific scores were obtained with a focus on the positive affect (See also Britton et al., 2014). Mindfulness training was shown to increase positive affect (Anderson et al., 2007; Nyklíček \& Kuijpers, 2008; Ortner et al., 2007) and shifts in positive affect due to treatment may be more pronounced in nonclinical populations (RobertsWolfe, Sacchet, Hastings, Roth, \& Britton, 2012), such as our current sample. Furthermore, given the important role of positive affect as an early indicator of depression onset (Wood \& Joseph, 2010) and growing evidence on the efficacy of interventions that aim at cultivating positive affect (Sin \& Lyubomirsky, 2009), we created STAI positive affect subscale scores by summing the 10 positive affect items. The internal consistency for the global $\left(\alpha_{\text {mean }}=0.94, \alpha_{\text {range }}=0.92-0.96\right)$ and positive scores ( $\alpha$ mean $=0.88$, $\left.\alpha_{\text {range }}=0.83-0.92\right)$ in the current study across all sessions was high.

\subsubsection{Mindfulness}

Mindfulness was assessed in relations to changes in affect using the 12-item Cognitive and Affective Mindfulness Scale (CAMS-R; Hayes \& Feldman, 2004). CAMS-R assesses an individual's ability to regulate attention, maintain an awareness of present-moment experience, and maintain an attitude of acceptance or non-judgment toward experience, rated on a scale from 1 (rarely) to 4 (almost always). Example items include "I am able to focus on the present moment," and "I can accept things I cannot change." The scores were coded for higher values to reflect higher mindfulness. The scale's internal consistency in the current study across sessions $\left(\alpha_{\text {mean }}=0.76, \alpha_{\text {range }}=0.73-0.80\right.$ ) was acceptable. CAMS-R was previously shown to have high reliability and validity (Feldman, Hayes, Kumar, Greeson, \& Laurenceau, 2007).

\subsubsection{Self-compassion}

Self-Compassion was assessed in relations to changes in affect by the 26-item Self-Compassion Scale (SCS; Neff, 2003), assessing the degree to which an individual has a warm and accepting (vs. self-critical) attitude toward oneself. The SCS includes six subscales assessing different aspects of self-compassion (self-kindness, self-judgment, common humanity, isolation, mindfulness, over-identification), rated on 1 (almost never) to 5 (almost always) scale. A global self-compassion score that reflects the degree of compassionate attitudes toward the self was created by summing the scores across the subscales. The scale's internal consistency in the current study across sessions ( $\alpha_{\text {mean }}=0.81, \alpha_{\text {range }}=0.80-0.82$ ) was high.

\subsection{Analyses}

\subsubsection{Preliminary analyses}

All four dependent measures (global affect, positive affect, mindfulness, compassion) across two time points (pretest, posttest) were within the acceptable range of normality (skewness and kurtosis between \pm 1.0 ). Values 3.0 standard deviations above or below the mean $(<0.9 \%$ of data) were deemed outliers and winsorized (reassigned a value at the next highest or lowest value that was not an outlier; Dixon \& Yuen, 1974). All results remained parallel using non-winsorized raw scores. Missing data ( $N=1$, STAI at posttest) were imputed (reassigned the nearest available data point) using Last Observation Carried Forward analysis following CONSORT recommendations for intent-to-treat analysis (Schulz, Altman, \& Moher, 2010). Preliminary analyses were used to describe baseline characteristics and participant flow and adherence and to investigate any baseline group differences that might affect the main analyses.

\subsection{Main analyses}

The main analyses investigated the effect of the intervention on affect (STAI-C global affect, STAI-C positive affect), mindfulness (CAMS-R), and self-compassion (SCS) with a focus on gender difference. We conducted two Analyses of Variance (ANOVA) for repeated measures using group (mindfulness vs. control) and gender (male, female) as two between-factors and global affect disturbance and positive affect across the within-factor (pretest vs. posttest) each as an outcome variable. Considering the explorative approach of our study, the small sample size, and the current statistical reporting guidelines (Cumming, 2014; Kline, 2013; Moher et al., 2010; Wilkinson, 1999) recommend interpreting results according to effect size and not statistical significance testing or dichotomous $p$-value cut-offs, nonsignificant $(p \geq 0.05)$ differences with an effect size of $d>0.20$ are interpreted and discussed as meaningful (Kline, 2013; Moher et al., 2010; Wilkinson, 1999). Effect sizes are reported as Cohen's $d$ and interpreted in the following 
Table 3

Gender comparison of baseline global and positive affect (STAI-C), mindfulness (CAMS-R), and self-compassion (SCS) separated by year and condition.

\begin{tabular}{|c|c|c|c|c|c|c|c|c|c|}
\hline & & \multicolumn{3}{|c|}{ Males } & \multicolumn{3}{|c|}{ Females } & \multirow[t]{2}{*}{$t$} & \multirow[t]{2}{*}{$p$} \\
\hline & & $n$ & $M$ & $S E$ & $n$ & $M$ & $S E$ & & \\
\hline \multicolumn{10}{|l|}{ Global affect (STAI-C) } \\
\hline \multirow[t]{2}{*}{ Control } & Year 1 & 13 & 386 & 66 & 12 & 427 & 68 & -0.43 & 0.670 \\
\hline & Year 2 & 12 & 446 & 68 & 11 & 428 & 71 & 0.18 & 0.856 \\
\hline \multirow[t]{2}{*}{ Mindfulness meditation } & Year 1 & 13 & 429 & 66 & 13 & 425 & 66 & 0.05 & 0.960 \\
\hline & Year 2 & 16 & 497 & 59 & 10 & 455 & 75 & 0.44 & 0.661 \\
\hline \multicolumn{10}{|l|}{ Positive affect (STAI-C) } \\
\hline \multirow[t]{2}{*}{ Control } & Year 1 & 13 & 502 & 33 & 12 & 505 & 34 & -0.05 & 0.958 \\
\hline & Year 2 & 12 & 511 & 34 & 11 & 528 & 36 & -0.34 & 0.734 \\
\hline \multirow[t]{2}{*}{ Mindfulness meditation } & Year 1 & 13 & 472 & 33 & 13 & 515 & 33 & -0.91 & 0.364 \\
\hline & Year 2 & 16 & 485 & 30 & 10 & 496 & 38 & -0.22 & 0.825 \\
\hline \multicolumn{10}{|l|}{ Mindfulness (CAMS-R) } \\
\hline \multirow[t]{2}{*}{ Control } & Year 1 & 13 & 34.77 & 1.54 & 12 & 34.42 & 1.60 & 0.16 & 0.874 \\
\hline & Year 2 & 12 & 31.25 & 1.60 & 11 & 31.00 & 1.67 & 0.11 & 0.914 \\
\hline \multirow[t]{2}{*}{ Mindfulness meditation } & Year 1 & 13 & 34.54 & 1.54 & 13 & 33.39 & 1.54 & 0.53 & 0.597 \\
\hline & Year 2 & 16 & 31.88 & 1.39 & 10 & 32.30 & 1.76 & -0.19 & 0.850 \\
\hline \multicolumn{10}{|l|}{ Self-compassion (SCS) } \\
\hline \multirow[t]{2}{*}{ Control } & Year 1 & 13 & 3.23 & 0.17 & 12 & 3.03 & 0.18 & 0.81 & 0.418 \\
\hline & Year 2 & 12 & 3.13 & 0.18 & 11 & 3.24 & 0.19 & -0.41 & 0.679 \\
\hline \multirow[t]{2}{*}{ Mindfulness meditation } & Year 1 & 13 & 3.26 & 0.17 & 13 & 3.25 & 0.17 & 0.01 & 0.992 \\
\hline & Year 2 & 16 & 3.53 & 0.16 & 10 & 3.36 & 0.20 & 0.66 & 0.511 \\
\hline
\end{tabular}

manner: small $=0.20$, medium $=0.50$, and large $=0.80$ (Cohen, 2008). Bonferroni corrected post-hoc tests were conducted for follow-up pairwise comparisons for effect sizes $d>0.20$. All analyses were performed using the Statistical Package for Social Science software (SPSS; IBM Corporation).

\section{Results}

\subsection{Preliminary analysis}

The final sample for analysis included 100 participants in the mindfulness meditation $(N=52)$ and control $(N=48)$ groups. Participants in each group did not significantly differ with respect to age or gender ( $p s>0.10$ ), or in baseline measures of emotional wellbeing, mindfulness and self-compassion ( $p s>0.10$; Table 2). We ran four $2 \times 2 \times 2$ ANOVAs using group (mindfulness vs. control), gender (male, female) and year $(1,2)$ as three between-factors for the baseline outcomes of global affect, positive affect, mindfulness and compassion (see Table 3 for descriptive data). At baseline, there was no significant effect of group or gender for any of the four variables (all $p>0.10$ ). Regarding year, there was no significant effect for global affect, positive affect, and self-compassion (all $p>0.10$ ). Students in year 1 were more mindful in comparison to those in year $2, F(1,92)=5.69, p=0.019$; year $1: M$ $(S E)=34.28$ (0.79); year 2: 31.61 (0.81). There was no significant interaction effect for any of the outcomes ( $p$ s $>0.10)$.

At baseline STAI, ten students scored above the suggested cut point for detecting clinically significant symptoms of anxiety (40, equivalent to 750 using our scoring method; Julian, 2011). Using a higher cut score of 55 suggested by Kvaal, Ulstein, Nordhus, and Engedal (2005), two students scored above the clinically significant anxiety symptoms. All results remained parallel excluding clinically anxious students using both cut points.

\subsection{Main analysis}

\subsubsection{Effect of mindfulness intervention on emotional wellbeing among early adolescents}

As previously reported by Britton et al., 2014 using the same sample, significant group (mindfulness, control) x time (pretest, posttest) interactions were detected for global affect disturbance with a small to medium effect size, $F(1,96)=3.97, p=0.05$, $d=0.41$, and positive affect with a small to medium effect size, $F(1,96)=4.33, p=0.04, d=0.41$. Pairwise comparisons between groups showed that meditators $\left(M_{\text {difference }}=-98.63\right.$ and $-60.73, S D_{\text {difference }}=27.63$ and 14.86 for global disturbances and positive affect, respectively) showed significant decreases in global affect disturbances $(p<0.001)$ and increases in positive affect $(p=0.001)$, whereas those in the control group show no significant improvement in affect $(p s>0.20)$.

3.2.1.1. Q1: Gender effects in response to interventions. We tested whether there was a group (mindfulness, control) $\mathrm{x}$ time (pretest, posttest) $\mathrm{x}$ gender (male, female) interaction with greater affective improvement due to mindfulness training among females compared to their male counterparts. Non-significant three-way interactions were detected for global affect disturbance, $F(1$, $96)=0.70, p=0.40, d=0.17$, and positive affect with a small to medium effect size, $F(1,96)=1.83, p=0.18, d=0.29$. 
Table 4

Descriptive statistics of the pre to post affect scores across gender and treatment groups.

\begin{tabular}{|c|c|c|c|c|c|c|c|}
\hline & & \multicolumn{3}{|l|}{ Males $(n=54)$} & \multicolumn{3}{|l|}{ Females $(n=46)$} \\
\hline & & Pre & Post & Stat $(F)$ & Pre & Post & Stat $(F)$ \\
\hline \multirow[t]{2}{*}{ Global affect (STAI-C) } & Mindfulness & $466.62(204.79)$ & $364.04(257.02)$ & $7.73^{* *}$ & $437.87(246.91)$ & $335.78(238.56)$ & $3.28^{*}$ \\
\hline & Control & $414.92(207.95)$ & 371.45 (228.50) & $4.29^{* *}$ & $427.30(274.20)$ & $434.00(299.08)$ & 0.04 \\
\hline \multirow[t]{2}{*}{ Positive affect (STAI-C) } & Mindfulness & 479.14 (114.35) & $537.86(127.28)$ & $10.04^{* *}$ & 506.35 (122.77) & 569.09 (117.98) & $5.24^{* * *}$ \\
\hline & Control & $506.56(108.67)$ & $550.24(125.55)$ & $6.64^{* * *}$ & 515.96 (122.49) & $507.70(143.38)$ & 0.19 \\
\hline
\end{tabular}

Note. STAI-C = Spielberger Anxiety Inventory-Child version. Mean values are displayed with standard deviations in parentheses where applicable.

${ }^{*} p<0.10$.

** $p<0.05$.

Because the effect size for positive affect was $>0.2$, and based on the positive results linking mindfulness to affect and our theoretical framework on gender-based divergent outcomes, exploratory follow-up pairwise comparisons were examined to identify the source of potential gender effects (see Table 4 for means; no follow-up analysis was conducted for the global disturbance $[d<0.2]$, but the related means are included in Table 4). Male participants in both mindfulness $\left(\boldsymbol{M}_{\mathrm{difference}}=58.72\right.$, $\left.S D_{\text {difference }}=19.11\right)$ and control $\left(M_{\text {difference }}=43.68, S D_{\text {difference }}=20.58\right)$ groups showed increases in positive affect regardless of the intervention group assignment $\left(p s=0.003,0.036\right.$, respectively). In contrast, female meditators ( $M_{\mathrm{difference}}=62.74$, $\left.S D_{\text {difference }}=21.45\right)$ showed improvements in positive affect $(p=0.004)$, whereas control females $\left(M_{\text {difference }}=-8.26\right.$, $\left.S D_{\text {difference }}=21.45\right)$ showed no change across the pre-to-post intervention period $(p=0.70)$ (Fig. 1).

3.2.1.2. Q2. Gender effects in potential mechanisms: mindfulness and compassion. Contrary to previous findings that showed reliable effects of mindfulness training on increases in mindfulness (Chambers et al., 2008; Zeidan et al., 2010) and self-compassion (Birnie et al., 2010; Kok \& Singer, 2016; Neff, 2003), no main effects of treatment group were present for changes in mindfulness and selfcompassion $(p s>0.70)$. One possibility might be that there was a wide variability in the response to the mindfulness and control interventions in influencing these variables. To test this, independent of treatment groups, we examined changes in mindfulness and self-compassion in relations to changes in affect among all participants as an exploratory effort to identify potential mechanisms of gender effect in affect changes. Correlation analyses revealed that for all participants, changes in affect was not correlated with changes in self-compassion or mindfulness ( $p s>0.20$ ).

To further investigate the potential gender difference in associations between affect and mindfulness and self-compassion, additional correlation analyses were performed separately for each gender (Table 5). Among all female participants, increases in selfcompassion were associated with decreases in global affect disturbance, $r(46)=-0.44, p=0.002$, and positive affect, $r(46)=0.39$, $p=0.008$ (Fig. 2). Changes in mindfulness, in contrast, were not associated with changes in global disturbance, $r(46)=-0.07$, $p=0.63$, or positive affect $r(46)=0.16, p=0.28$.

No significant links between mindfulness, compassion and affect were detected in male participants; global affect disturbance and positive affect, respectively, were not significantly associated with changes in self-compassion $r(54)=0.21,-0.12, p=0.13,0.37$ (Fig. 2), or mindfulness $r(54)=-0.15,0.10, p=0.29,0.46$.

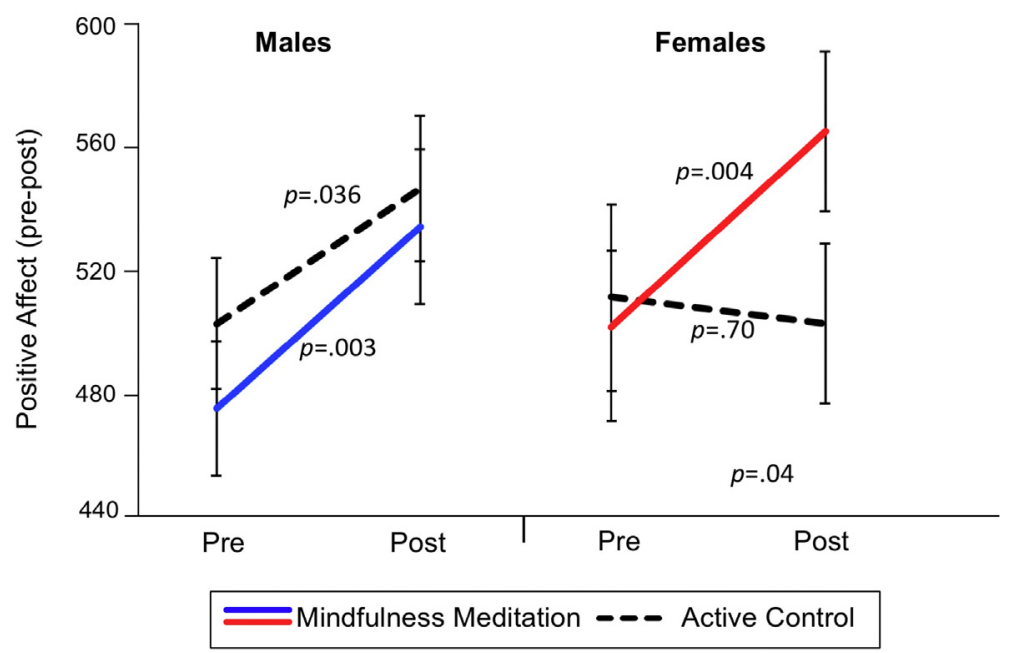

Fig. 1. Gender differences in responses to the mindfulness meditation and control interventions. All male participants showed increases in positive affect regardless of the intervention group assignment. In contrast, female meditators showed improvements in positive affect compared to female controls that showed no change across the pre-to-post intervention period. 
Table 5

Zero-order correlations: pre-post change scores of study variables in meditators, split by gender.

\begin{tabular}{|c|c|c|c|c|c|}
\hline & & Global affect (STAI-C) & Positive affect (STAI-C) & Mindfulness (CAMS-R) & Self-compassion (SCS) \\
\hline \multirow[t]{4}{*}{ Males $(n=29)$} & Global affect & - & $-0.82^{* *}$ & -0.15 & 0.21 \\
\hline & Positive affect & & - & 0.10 & -0.12 \\
\hline & Mindfulness & & & - & 0.14 \\
\hline & Self-compassion & & & & - \\
\hline \multirow{4}{*}{$\begin{array}{l}\text { Females } \\
\qquad(n=23)\end{array}$} & Global affect & - & $-0.88^{* *}$ & -0.07 & $-0.44 * *$ \\
\hline & Positive affect & & - & 0.16 & $0.39^{* *}$ \\
\hline & Mindfulness & & & - & $0.08^{* *}$ \\
\hline & Self-compassion & & & & - \\
\hline
\end{tabular}

Note. CAMS-R = Cognitive and Affective Mindfulness Scale-Revised; SCS = Self-Compassion Scale; STAI-C = Spielberger Anxiety Inventory-Child version.

*** $p<0.01$.

Females

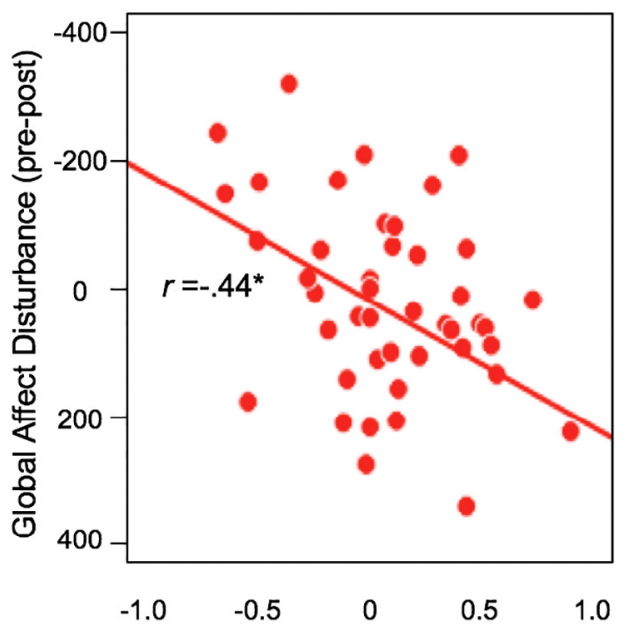

Males

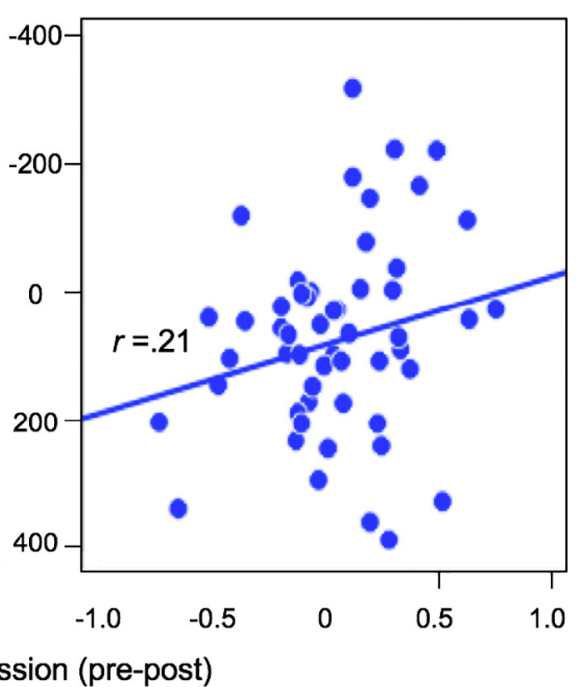

Fig. 2. Gender differences in correlations between self-compassion and affect changes in all participants. Increases in self-compassion were associated with decreases in global affect disturbance among females (red); no significant correlations were obtained among males (blue), ${ }^{*} p<0.01$. (For interpretation of the references to color in this figure legend, the reader is referred to the web version of this article.)

\section{Discussion}

The current study examined the gender difference in responses to school-based mindfulness training in early adolescents. While mindfulness training was associated with improved emotional wellbeing compared to those in the control group, the effects differed according to gender. Specifically, female meditators showed greater improvement in emotional wellbeing compared to control females, whereas the meditation group showed no greater improvement over the control group among male participants. In addition, only female, but not male, meditators showed a correlation between improvements in affect and increases self-compassion.

\subsection{Gender differences in response to the mindfulness and active control interventions}

For female participants, the meditation group showed improvement in affect compared to the control group. Among male participants however, the benefit was comparable among those in meditation and control groups; participants in both groups reported significantly improved affect pre-to-post intervention. Furthermore, control males showed marginally greater improvement in positive affect compared to control females, suggesting that the control intervention may have been more favorable to males than to females. The active control module was only distinguished from the meditation module by the substitution of African history class for Asian history (e.g., mindfulness training). Therefore, these discrepancies may be attributable to gender differences in response to the control intervention (e.g. building a sarcophagus).

The unexpected change in affect for males in the control group may suggest that the control activity might have been uniquely effective for male students. For instance, the external activity in the control intervention might have better accommodated the external coping strategy more typical of male adolescents (Butler \& Nolen-Hoeksema, 1994; Li, DiGiuseppe, \& Froh, 2006; Rose, 
2002), and previous research suggests that individuals with higher masculinity ratings tend to respond better to physically active forms of stress reduction (Friedman \& Berger, 1991).

The control activity was not sufficient to impede a natural course of female students' affective decline around the age 11 to 12 when emotional disturbances tend to emerge in females. Conversely, the significant effect of mindfulness on improved affect in females may reflect that mindfulness is an effective tool to prevent the usual decline for females. For males, the equal gain in affect across groups may suggest multiple possible interpretations that will require further research to differentiate. For example, the male and female students might have responded differently to self-report measures with varying degrees of social desirability bias (e.g., Hebert et al., 1997). It is also possible that male students might have benefitted more with active methods of mindfulness training, such as yoga or Tai Chi, compared to silent meditation training without movement (e.g., Rojiani et al., 2017). However, the current study did not assess participants' coping strategies, levels of engagement/distraction during the class activities, or other potential covariates that might have affected responses to different forms of mindfulness training. Future studies may include more comprehensive measures of coping to test such possibilities.

\subsection{Potential gender differences in mechanisms}

In terms of mechanisms, changes in mindfulness were not associated with affect changes for both gender. Instead, a more affectbased mechanism involving self-compassion was detected, such that increases in self-compassion were associated with improved affect only among female but not male meditators. In particular, a strong correlation between self-compassion and affect was present among female students whereas no such association was obtained among male counterparts. These findings are largely consistent with extant literature that suggests females tend to rely on affective coping strategies (e.g., Mendlowitz et al., 1999), and with previous findings that showed affective improvement in mindfulness training in female (but not male) adults correlated with increases in self-compassion. Because self-criticism tends to be more common among female than male youths and is generally harmful to affective health (Calvete \& Cardeñoso, 2005; Nolen-Hoeksema \& Girgus, 1994), self-compassion, as an antidote to self-criticism, may provide greater impact on emotional wellbeing among females than males. Female adolescents may particularly benefit from interventions that target self-criticism to increase self-compassion. This finding potentially informs effective strategies for school psychologists to target negative affectivity among female adolescents. More generally, these findings suggest that the mechanisms for females may perform in a manner that is consistent with the general model of mindfulness, whereas the predictors of benefit for males may not the ones commonly specified for mindfulness.

However, we note that the current model of mindfulness (ICP) teaches attention allocation without the strong emphasis on selfcompassion that is part of other mindfulness programs such as mindfulness-based stress reduction program (MBSR) or mindfulnessbased cognitive therapy (MBCT). These programs that emphasize acceptance and non-judgment would more likely lead to increases in compassion, which may lead to even larger gender effects than the ICP program. Therefore, we encourage future studies to examine gender as an active treatment moderator in other standard mindfulness programs.

\subsection{Mindfulness in school psychology}

Although mindfulness was shown to be a promising strategy to promote mental health in youths (for meta-analyses, see Black et al., 2009; Kallapiran et al., 2015; Zenner et al., 2014; Zoogman et al., 2015), school psychology has yet to embrace mindfulness in practice. In implementing and evaluating school-based intervention programs, school psychologists play major roles in various stages and components of the program, including small group interventions, classroom consultation, and program evaluation. Therefore, a careful investigation in youth populations is warranted under the supervision of school psychologists. As such, school psychologists were involved to address mental health needs of the students in the current study. Beyond integrating school psychologists in schoolbased mindfulness intervention programs, we further encourage mindfulness studies in the field of school psychology. This is essential especially given the vulnerable nature of the adolescent population and potentially lasting impact of school-based interventions.

Furthermore, findings from school-based mindfulness intervention can provide practical implications for school psychologists. For example, the current results suggest that mindfulness interventions can be especially beneficial for female students in terms of promoting affective health, and that female students may particularly benefit by focusing on cultivating self-compassion. Future studies that include in-depth first-person reports and interviews conducted by school psychologists are warranted to triangulate the component processes of the affective mechanism of mindfulness effect among female youths and to develop more effectively tailored intervention strategies.

\subsection{Study limitations}

Findings from the present study should be interpreted within the confines of general limitations regarding the measures, sample selection, and intervention design. First, all measures were based on self-reports and subject to demand characteristic and expectancy effects. We encourage future studies to employ additional behavior observations and other objective laboratory measures. Second, the response format of STAI was modified from Likert to a visual analog to allow for examination of affect along a continuous spectrum, which may challenge its validity and generalizability. Third, the current study was conducted in a private Quaker school and likely includes students from high-income and Caucasian backgrounds who are familiar with contemplative practices (e.g., Quaker meetings); thus the shown effects should be tested in more nationally representable samples. In addition, although all main analysis 
included the baseline STAI scores as a covariate to control for the initial differences in affect, the current study did not investigate the number of students qualified for special education services under the emotional disturbance category. Given that ten students out of 100 met the clinical cut off point for anxiety in our current sample, and because mindfulness intervention may be more or less efficacious depending on the baseline severity of symptoms, we encourage future studies to consider more class-specific data when administering school-based interventions. Fourth, treatment fidelity or intervention integrity was not assessed, and the degree of teachers' and students' adherence to protocols could not be monitored. Furthermore, the durations for each meditation session and the types of practices students chose during the last third of the curriculum are unknown, making it difficult to attribute the shown effects to specific components of the intervention (e.g., Century, Rudnick, \& Freeman, 2010; Gould, Dariotis, Greenberg, \& Mendelson, 2016). To assess intervention success with rigor and to promote replicability, we encourage future studies to include both qualitative and quantitative measures of intervention assessment and the training of the interventionists. Fifth, the average minutes of meditation in the current intervention ( $5 \mathrm{~min} /$ day) was substantially shorter than those recommended by other conventional mindfulness interventions designed for adults ( $45 \mathrm{~min} /$ day in MBSR). Although significant effects have been reported with the 5-10 min of daily meditation among adolescent populations (Britton et al., 2010; Fernando \& Keller, 2012; Saltzman \& Goldin, 2008; Zylowska et al., 2008), examining the impact of increased meditation minutes during class and homework may help identify ideal meditation dosage for children. Sixth, students were nested within four classrooms and the potential impact of classroom assignment cannot be addressed. The sample size per cell was not sufficient for multilevel modeling, so we were not able to identify potential impact of classroom placement, although all classes were taught by the same teachers and teacher assignment is controlled for. The difference between the active control and intervention group was not only a meditation-based practice but also the content of the didactic instruction (African vs. Asian history). Although it is unlikely that this would influence our outcome, it still needs to be considered as possible confound.

We further note limitations regarding gender-specific effects. Our current sample, with the comparable baseline affect scores across male and female students, may not be sufficiently representative of early adolescent populations. For example, in a larger scale study with a non-clinical sample of 830 children in early adolescence (mean age $=12.9$ ), female participants reported significantly greater global negative affect measured by STAI-C $(M=33.1, S D=7.5)$ compared to male participants $(M=29.4, S D=6.5)$, $t=7.2, p<0.001$ (Roelofs et al., 2009). In contrast, within our sample the baseline global negative affect scores for female $(M=23.07, S D=13.76)$ and male students $(M=23.61, S D=10.98)$ were statistically equivalent, $t(98)=0.22, p=0.83($ Mean and standard deviation scores from the current study are converted to the standard 0-80 scale for the ease of interpretation). We suggest two possibilities that may explain the lack of baseline gender differences in affect. First, given that the current sample included children nearing onset of puberty (10 or 11 for girls and age 11 or 12 for boys [Kail \& Cavanaugh, 2010]), the time when gender difference in affective symptoms tends to emerge, female students in our sample may not have begun to experience negative affect symptoms. Second, it is also possible that females in our sample were affectively highly functioning regardless of age. Students were drawn from a private middle school in a surrounding neighborhood of predominantly higher socioeconomic class, with potentially greater access to psychosocial resources and support compared to the general population (Murali \& Oyebode, 2004; Raymore, Godbey, \& Crawford, 1994). Since mindfulness training targets negative affect and maladaptive affect processing, it may function as a preventative measure rather than treatment for emotionally healthy females. Therefore, a more representative, older sample of adolescents that exhibit greater baseline differences in affect may respond with greater gender divergence in response to intervention. We thus encourage future studies to test gender difference in mindfulness training in larger scale across diverse populations of young people. Nonetheless, the lack of baseline differences in affect suggests that the shown gender differences were due to differential responses to intervention and not the baseline differences.

In addition, the control intervention yielded specific benefits among male but not female students as elaborated above. We encourage future studies to test specific factors responsible for affective improvements among male adolescents that may be associated with creative classroom activities similar to the control intervention in this study. This also highlights the importance of considering gender as an outcome modifier when designing control conditions in mindfulness research. Finally, our sample consisted only of cisgendered (i.e., gender corresponds with birth sex) participants. Future examination of mindfulness effects among nonbinary, gender fluid and transgender youths is warranted.

\section{Conclusion}

Early adolescence presents unique developmental challenges that may unfavorably affect later mental health. The current study demonstrated that mindfulness training can be successfully integrated into a middle school education curriculum, and calls for affecttargeting school-based intervention strategies at this young age. Extending our previous work on gender differences in response to mindfulness training in college samples, with female students being especially responsive (Rojiani et al., 2017), this is the first study to replicate these findings in youths. However, in light of insignificant results with small to medium effect size, we caution against conclusively mapping results from the current data to aspects of existing theories or drawing conclusive claims about gender effects in mindfulness studies. Instead, our study provides initial insights regarding gender-sensitive application of mindfulness training in school, and potential benefits of considering gender-tailored modules that may enhance existing mindfulness training programs. This work highlights the potential role of gender in modulating the effectiveness of mindfulness training, and the complex pathways through which gender might exert effects on affect outcomes. More broadly, treatment outcome modifiers including gender should be carefully considered in future intervention strategies among young populations. 


\section{Acknowledgments}

This study includes the same sample that were used in the previous pilot trial by Britton et al., 2014; no novel data were collected, which should be noted in considering external validity of the current findings. In addition, we note that the current study was not initially designed to examine gender difference; rather, a recent finding of gender effects in the context of mindfulness training prompted additional analyses in the current report. This work was supported by the National Institutes of Health (grant K23AT006328-01A1); the National Institutes of Health (NIH) Science of Behavior Change Common Fund Program through an award administered by the National Center for Complementary and Integrative Health (grant UH2AT009145); The Lenz Foundation, The Hershey Foundation; the Mind and Life Institute; and the Brown University Contemplative Studies Initiative. The views presented here are solely the responsibility of the authors and do not necessarily represent the official views of the NIH. We would also like to thank the Clinical and Affective Neuroscience Laboratory at Brown University. This was not an industry-supported study. The authors have indicated no financial conflicts of interest.

\section{References}

Anderson, N. D., Lau, M. A., Segal, Z. V., \& Bishop, S. R. (2007). Mindfulness-based stress reduction and attentional control. Clinical Psychology \& Psychotherapy, 14(6), 449-463.

Baer, R. A. (2003). Mindfulness training as a clinical intervention: A conceptual and empirical review. Clinical Psychology: Science and Practice, 10(2), 125-143.

Beauchemin, J., Hutchins, T. L., \& Patterson, F. (2008). Mindfulness meditation may lessen anxiety, promote social skills, and improve academic performance among adolescents with learning disabilities. Complementary Health Practice Review, 13(1), 34-45.

Bender, P. K., Reinholdt-Dunne, M. L., Esbjørn, B. H., \& Pons, F. (2012). Emotion dysregulation and anxiety in children and adolescents: Gender differences. Personality and Individual Differences, 53(3), 284-288.

Biegel, G. M., Brown, K. W., Shapiro, S. L., \& Schubert, C. M. (2009). Mindfulness-based stress reduction for the treatment of adolescent psychiatric outpatients: A randomized clinical trial. Journal of Consulting and Clinical Psychology, 77(5), 855.

Bieling, P. J., Antony, M. M., \& Swinson, R. P. (1998). The state-trait anxiety inventory, trait version: Structure and content re-examined. Behaviour Research and Therapy, 36(7), 777-788.

Birnie, K., Speca, M., \& Carlson, L. E. (2010). Exploring self-compassion and empathy in the context of mindfulness-based stress reduction (MBSR). Stress and Health, 26(5), 359-371.

Black, D. S., Milam, J., \& Sussman, S. (2009). Sitting-meditation interventions among youth: A review of treatment efficacy. Pediatrics, 124(3), e532-e541.

Bögels, S., Hoogstad, B., van Dun, L., de Schutter, S., \& Restifo, K. (2008). Mindfulness training for adolescents with externalizing disorders and their parents. Behavioural and Cognitive Psychotherapy, 36(02), 193-209.

Bootzin, R. R., \& Stevens, S. J. (2005). Adolescents, substance abuse, and the treatment of insomnia and daytime sleepiness. Clinical Psychology Review, 25(5), 629-644.

Briere, F. N., Rohde, P., Stice, E., \& Morizot, J. (2016). Group-based symptom trajectories in indicated prevention of adolescent depression. Depression and Anxiety, 33, $444-451$.

Bringuier, S., Dadure, C., Raux, O., Dubois, A., Picot, M. C., \& Capdevila, X. (2009). The perioperative validity of the visual analog anxiety scale in children: A discriminant and useful instrument in routine clinical practice to optimize postoperative pain management. Anesthesia \& Analgesia, $109(3)$, $737-744$.

Britton, W. B., Bootzin, R. R., Cousins, J. C., Hasler, B. P., Peck, T., \& Shapiro, S. L. (2010). The contribution of mindfulness practice to a multicomponent behavioral sleep intervention following substance abuse treatment in adolescents: A treatment-development study. Substance Abuse, 31(2), 86-97.

Britton, W. B., Lepp, N. E., Niles, H. F., Rocha, T., Fisher, N. E., \& Gold, J. S. (2014). A randomized controlled pilot trial of classroom-based mindfulness meditation compared to an active control condition in sixth-grade children. Journal of School Psychology, 52(3), 263-278.

Broderick, P. C., \& Metz, S. (2009). Learning to BREATHE: A pilot trial of a mindfulness curriculum for adolescents. Advances in School Mental Health Promotion, 2(1), $35-46$.

Brooks-Gunn, J., \& Petersen, A. C. (1991). Studying the emergence of depression and depressive symptoms during adolescence. Journal of Youth and Adolescence, 20(2), 115-119.

Burke, C. A. (2010). Mindfulness-based approaches with children and adolescents: A preliminary review of current research in an emergent field. Journal of Child and Family Studies, 19(2), 133-144.

Butler, L. D., \& Nolen-Hoeksema, S. (1994). Gender differences in responses to depressed mood in a college sample. Sex Roles, 30(5-6), 331-346.

Caci, H., Baylé, F. J., Mattei, V., Dossios, C., Robert, P., \& Boyer, P. (2003). How does the hospital and anxiety and depression scale measure anxiety and depression in healthy subjects? Psychiatry Research, 118(1), 89-99.

Calvete, E., \& Cardeñoso, O. (2005). Gender differences in cognitive vulnerability to depression and behavior problems in adolescents. Journal of Abnormal Child Psychology, 33(2), 179-192.

Card, N. A., \& Hodges, E. V. E. (2008). Peer victimization among schoolchildren: Correlations, causes, consequences, and considerations in assessment and intervention. School Psychology Quarterly, 23, 451-461.

Carter, A. S., Wagmiller, R. J., Gray, S. A., McCarthy, K. J., Horwitz, S. M., \& Briggs-Gowan, M. J. (2010). Prevalence of DSM-IV disorder in a representative, healthy birth cohort at school entry: Sociodemographic risks and social adaptation. Journal of the American Academy of Child \& Adolescent Psychiatry, 49(7), 686-698.

Century, J., Rudnick, M., \& Freeman, C. (2010). A framework for measuring fidelity of implementation: A foundation for shared language and accumulation of knowledge. American Journal of Evaluation, 31(2), 199-218.

Chambers, R., Lo, B. C. Y., \& Allen, N. B. (2008). The impact of intensive mindfulness training on attentional control, cognitive style, and affect. Cognitive Therapy and Research, 32(3), 303-322.

Clark, L. A., Watson, D., \& Mineka, S. (1994). Temperament, personality, and the mood and anxiety disorders. Journal of Abnormal Psychology, $103,103$.

Code of Federal Regulations (2004). Title 34, \$300.8(c)(4)(ii).

Cohen, B. H. (2008). Explaining psychological statistics. John Wiley \& Sons.

Cumming, G. (2014). The new statistics: Why and how. Psychological Science, 25(1), 7-29.

Currie, C., Roberts, C., Morgan, A., Smith, R., Settertobulte, W., \& Samdal, O. (2002). Young people's health in context. Health Behavior in School-Aged Children (HBSC) study: International report from the 2001/2002 survey. Kopenhagen. Retrieved from WHO website Available online at: http://www.euro.who.int/_data/ assets/pdf_file/0008/110231/e82923.pdf.

Deardorff, J., Hayward, C., Wilson, K. A., Bryson, S., Hammer, L. D., \& Agras, S. (2007). Puberty and gender interact to predict social anxiety symptoms in early adolescence. Journal of Adolescent Health, 41(1), 102-104.

De Boo, G. M., \& Spiering, M. (2010). Pre-adolescent gender differences in associations between temperament, coping, and mood. Clinical Psychology \& Psychotherapy, 17(4), 313-320.

de Vibe, M., Solhaug, I., Tyssen, R., Friborg, O., Rosenvinge, J. H., Sørlie, T., \& Bjørndal, A. (2013). Mindfulness training for stress management: A randomised controlled study of medical and psychology students. BMC Medical Education, 13(1), 107.

Desbordes, G., Negi, L. T., Pace, T. W., Wallace, B. A., Raison, C. L., \& Schwartz, E. L. (2012). Effects of mindful-attention and compassion meditation training on amygdala response to emotional stimuli in an ordinary, non-meditative state. Frontiers in Human Neuroscience, 6, 292.

Dixon, W., \& Yuen, K. (1974). Trimming and winsorization: A review. Statistical Papers, 15(2), 157-170. 
Else-Quest, N. M., Hyde, J. S., Goldsmith, H. H., \& Van Hulle, C. A. (2006). Gender differences in temperament: A meta-analysis. Psychological Bulletin, 132(1).

Essau, C. A., Lewinsohn, P. M., Seeley, J. R., \& Sasagawa, S. (2010). Gender differences in the developmental course of depression. Journal of Affective Disorders, 127(1), 185-190.

Feldman, G., Hayes, A., Kumar, S., Greeson, J., \& Laurenceau, J. P. (2007). Mindfulness and emotion regulation: The development and initial validation of the Cognitive and Affective Mindfulness Scale-Revised (CAMS-R). Journal of Psychopathology and Behavioral Assessment, 29(3), 177-190.

Felver, J. C., Celis-de Hoyos, C. E., Tezanos, K., \& Singh, N. N. (2016). A systematic review of mindfulness-based interventions for youth in school settings. Mindfulness, $7(1), 34-45$.

Felver, J. C., Doerner, E., Jones, J., Kaye, N. C., \& Merrell, K. W. (2013). Mindfulness in school psychology: Applications for intervention and professional practice. Psychology in the Schools, 50(6), 531-547.

Fernando, R., \& Keller, S. (2012). Measuring the efficacy and sustainability of the mindful schools mindfulness-based in-class intervention. Paper presented at the 10th Annual International Scientific Conference: Investigating and integrating mindfulness in medicine, health care, and society; Norwood, MA.

Foster, R. L., \& Park, J. H. (2012). An integrative review of literature examining psychometric properties of instruments measuring anxiety or fear in hospitalized children. Pain Management Nursing, 13(2), 94-106.

Friedman, E., \& Berger, B. G. (1991). Influence of gender, masculinity, and femininity on the effectiveness of three stress reduction techniques: Jogging, relaxation response, and group interaction. Journal of Applied Sport Psychology, 3(1), 61-86.

Gould, L. F., Dariotis, J. K., Greenberg, M. T., \& Mendelson, T. (2016). Assessing fidelity of implementation (FOI) for school-based mindfulness and yoga interventions: A systematic review. Mindfulness, 7(1), 5-33.

Graham, R. A., \& Weems, C. F. (2015). Identifying moderators of the link between parent and child anxiety sensitivity: The roles of gender, positive parenting, and corporal punishment. Journal of Abnormal Child Psychology, 43(5), 885-893.

Greenberg, M. T., \& Harris, A. R. (2012). Nurturing mindfulness in children and youth: Current state of research. Child Development Perspectives, 6(2), 161-166.

Grös, D. F., Antony, M. M., Simms, L. J., \& McCabe, R. E. (2007). Psychometric properties of the State-Trait Inventory for Cognitive and Somatic Anxiety (STICSA): Comparison to the State-Trait Anxiety Inventory (STAI). Psychological Assessment, 19(4), 369.

Hankin, B. L., Mermelstein, R., \& Roesch, L. (2007). Sex differences in adolescent depression: Stress exposure and reactivity models. Child Development, 78(1), 279-295.

Hayes, A. M., \& Feldman, G. (2004). Clarifying the construct of mindfulness in the context of emotion regulation and the process of change in therapy. Clinical Psychology: Science and Practice, 11(3), 255-262.

Hebert, J. R., Ma, Y., Clemow, L., Ockene, I. S., Saperia, G., Stanek, E. J., ... Ockene, J. K. (1997). Gender differences in social desirability and social approval bias in dietary self-report. American Journal of Epidemiology, 146(12), 1046-1055.

Hofmann, S. G., Sawyer, A. T., Witt, A. A., \& Oh, D. (2010). The effect of mindfulness-based therapy on anxiety and depression: A meta-analytic review. Journal of Consulting and Clinical Psychology, 78(2), 169-183.

Hollis-Walker, L., \& Colosimo, K. (2011). Mindfulness, self-compassion, and happiness in non-meditators: A theoretical and empirical examination. Personality and Individual Differences, 50(2), 222-227.

Julian, L. J. (2011). Measures of anxiety: State-Trait Anxiety Inventory (STAI), Beck Anxiety Inventory (BAI), and Hospital Anxiety and Depression Scale-Anxiety (HADS-A). Arthritis Care \& Research, 63(S11), S467-S472.

Kabat-Zinn, J. (1990). Full catastrophe living: The program of the stress reduction clinic at the University of Massachusetts Medical Center. New York: Delta.

Kail, R. V., \& Cavanaugh, J. C. (2010). Human development: A life span view. Cengage Learning, 269.

Kallapiran, K., Koo, S., Kirubakaran, R., \& Hancock, K. (2015). Effectiveness of mindfulness in improving mental health symptoms of children and adolescents: A metaanalysis. Child and Adolescent Mental Health, 20(4), 182-194.

Kang, Y., Gruber, J., \& Gray, J. R. (2013). Mindfulness and de-automatization. Emotion Review, 5(2), $192-201$.

Kang, Y., Gruber, J., \& Gray, J. R. (2014). Mindfulness: Deautomatization of cognitive and emotional life. The Wiley Blackwell handbook of mindfulness (pp. 168-185). .

Katz, D., \& Toner, B. (2013). A systematic review of gender differences in the effectiveness of mindfulness-based treatments for substance use disorders. Mindfulness, 4(4), 318-331.

Kessler, R. C., Avenevoli, S., Costello, E. J., Georgiades, K., Green, J. G., Gruber, M. J., ... Sampson, N. A. (2012). Prevalence, persistence, and sociodemographic correlates of DSM-IV disorders in the National Comorbidity Survey Replication Adolescent Supplement. Archives of General Psychiatry, 69(4), 372-380.

Kline, R. B. (2013). Beyond significance testing: Statistics reform in the behavioral sciences. American Psychological Association.

Kok, B. E., \& Singer, T. (2016). Phenomenological fingerprints of four meditations: Differential state changes in affect, mind-wandering, meta-cognition, and interoception before and after daily practice across 9 months of training. Mindfulness, 1-14.

Kvaal, K., Ulstein, I., Nordhus, I. H., \& Engedal, K. (2005). The Spielberger state-trait anxiety inventory (STAI): The state scale in detecting mental disorders in geriatric patients. International Journal of Geriatric Psychiatry, 20(7), 629-634.

Lewinsohn, P. M., Gotlib, I. H., Lewinsohn, M., Seeley, J. R., \& Allen, N. B. (1998). Gender differences in anxiety disorders and anxiety symptoms in adolescents. Journal of Abnormal Psychology, 107(1).

Li, C. E., DiGiuseppe, R., \& Froh, J. (2006). The roles of sex, gender, and coping in adolescent depression. Adolescence, 41(163).

Liehr, P., \& Diaz, N. (2010). A pilot study examining the effect of mindfulness on depression and anxiety for minority children. Archives of Psychiatric Nursing, 24(1), 69-71.

Lohaus, A., \& Ball, J. (2006). Gesundheit und Krankheit aus der Sicht von Kindern (2nd edn). Göttingen: Hogrefe.

Maynard, B. R., Solis, M., Miller, V., \& Brendel, K. E. (2017). Mindfulness-based interventions for improving cognition, academic achievement, behavior and socioemotional functioning of primary and secondary students. Campbell systematic reviews. 13.

McGrath, E. E., Keita, G. P. E., Strickland, B. R., \& Russo, N. F. E. (1990). Women and depression: Risk factors and treatment issues: Final report of the American Psychological Association's National Task Force on Women and Depression. American Psychological Association.

Mendelson, T., Greenberg, M. T., Dariotis, J. K., Gould, L. F., Rhoades, B. L., \& Leaf, P. J. (2010). Feasibility and preliminary outcomes of a school-based mindfulness intervention for urban youth. Journal of Abnormal Child Psychology, 38(7), 985-994.

Mendlowitz, S. L., Manassis, K., Bradley, S., Scapillato, D., Miezitis, S., \& Shaw, B. E. (1999). Cognitive-behavioral group treatments in childhood anxiety disorders: The role of parental involvement. Journal of the American Academy of Child \& Adolescent Psychiatry, 38(10), 1223-1229.

Merikangas, K. R., He, J. P., Burstein, M., Swanson, S. A., Avenevoli, S., Cui, L., ... Swendsen, J. (2010). Lifetime prevalence of mental disorders in US adolescents: results from the National Comorbidity Survey Replication-Adolescent Supplement (NCS-A). Journal of the American Academy of Child \& Adolescent Psychiatry, 49(10), 980-989.

Mezulis, A. H., Funasaki, K. S., Charbonneau, A. M., \& Hyde, J. S. (2010). Gender differences in the cognitive vulnerability-stress model of depression in the transition to adolescence. Cognitive Therapy and Research, 34(6), 501-513.

Moher, D., Hopewell, S., Schulz, K. F., Montori, V., Gotzsche, P. C., Devereaux, P. J., ... Altman, D. G. (2010). CONSORT 2010 explanation and elaboration: Updated guidelines for reporting parallel group randomised trials. Journal of Clinical Epidemiology, 340(mar23 1), c869-c869.

Murali, V., \& Oyebode, F. (2004). Poverty, social inequality and mental health. Advances in Psychiatric Treatment, 10(3).

Muris, P., Mayer, B., \& Schubert, T. (2010). "You Might Belong in Gryffindor": Children's Courage and Its Relationships to Anxiety Symptoms, Big Five Personality Traits, and Sex Roles. Child Psychiatry \& Human Development, 41(2), 204-213.

Napoli, M., Krech, P. R., \& Holley, L. C. (2005). Mindfulness training for elementary school students: The attention academy. Journal of Applied School Psychology, 21(1), 99-125.

Neff, K. (2003). Self-compassion: An alternative conceptualization of a healthy attitude toward oneself. Self and Identity, 2(2), 85-101.

Nolen-Hoeksema, S. (1987). Sex differences in unipolar depression: Evidence and theory. Psychological Bulletin, 101, $259-282$.

Nolen-Hoeksema, S., \& Girgus, J. S. (1994). The emergence of gender differences in depression during adolescence. Psychological Bulletin, 115(3).

Nyklíček, I., \& Kuijpers, K. F. (2008). Effects of mindfulness-based stress reduction intervention on psychological well-being and quality of life: Is increased mindfulness indeed the mechanism? Annals of Behavioral Medicine, 35(3), 331-240. 
Ortner, C. N., Kilner, S. J., \& Zelazo, P. D. (2007). Mindfulness meditation and reduced emotional interference on a cognitive task. Motivation and Emotion, 31(4), $271-283$.

Ospina, M. B., Bond, K., Karkhaneh, M., Tjosvold, L., Vandermeer, B., Liang, Y., ... Klassen, T. P. (2007). Meditation practices for health: State of the research. Evidence Report/TechnologyAassessment, 155(155), 1-263.

Paus, T., Keshavan, M., \& Giedd, J. N. (2008). Why do many psychiatric disorders emerge during adolescence? Nature Reviews Neuroscience, 9(12), 947-957.

Raymore, L. A., Godbey, G. C., \& Crawford, D. W. (1994). Self-esteem, gender, and socioeconomic status: Their relation to perceptions of constraint on leisure among adolescents. Journal of Leisure Research, 26(2).

Roberts-Wolfe, D., Sacchet, M., Hastings, E., Roth, H., \& Britton, W. B. (2012). Mindfulness training alters emotional memory recall compared to active controls: Support for an emotional information processing model of mindfulness. Frontiers in Human Neuroscience, 6.

Roelofs, J., Rood, L., Meesters, C., Te Dorsthorst, V., Bögels, S., Alloy, L. B., \& Nolen-Hoeksema, S. (2009). The influence of rumination and distraction on depressed and anxious mood: A prospective examination of the response styles theory in children and adolescents. European Child \& Adolescent Psychiatry, 18(10), 635-642.

Rojiani, R., Santoyo, J. F., Rahrig, H., Roth, H. D., \& Britton, W. B. (2017). Women benefit more than men in response to college-based meditation training. Frontiers in Psychology, 8.

Romano, E., Tremblay, R. E., Vitaro, F., Zoccolillo, M., \& Pagani, L. (2001). Prevalence of psychiatric diagnoses and the role of perceived impairment: Findings from an adolescent community sample. Journal of Child Psychology and Psychiatry, 42(4), 451-461.

Rose, A. J. (2002). Co-rumination in the friendships of girls and boys. Child Development, 73(6), 1830-1843.

Roth, H. (2014). A pedagogy for the new field of contemplative studies. Contemplative approaches to learning and inquiry across disciplines. $97-118$.

Rutter, M., Izard, C. E., \& Read, P. B. (1986). Depression in young people: Developmental and clinical perspectives. Guilford Press.

Saltzman, A., \& Goldin, P. (2008). Mindfulness-based stress reduction for school-age children. Acceptance and mindfulness interventions for children adolescents and families (pp. 139-161). .

Schonert-Reichl, K. A., \& Lawlor, M. S. (2010). The effects of a mindfulness-based education program on pre-and early adolescents' well-being and social and emotional competence. Mindfulness, 1(3), 137-151.

Schulz, K. F., Altman, D. G., \& Moher, D. (2010). CONSORT 2010 statement: Updated guidelines for reporting parallel group randomised trials. BMC Medicine, 8(1).

Segal, Z. V., Williams, J. M. G., \& Teasdale, J. D. (2002). Mindfulness-based cognitive therapy for depression: A new approach to relapse prevention. New York: Guilford.

Shapiro, S. L., Astin, J. A., Bishop, S. R., \& Cordova, M. (2005). Mindfulness-based stress reduction for health care professionals: Results from a randomized trial. International Journal of Stress Management, 12, 164-176.

Shapiro, S. L., Brown, K. W., \& Astin, J. A. (2008). Toward the integration of meditation into higher education: A review of research. The center for contemplative mind in society. Retrieved from http://www.contemplativemind.org/admin/wp-content/uploads/2012/09/MedandHigherEd.pdf.

Sibinga, E. M., Kerrigan, D., Stewart, M., Johnson, K., Magyari, T., \& Ellen, J. M. (2011). Mindfulness-based stress reduction for urban youth. The Journal of Alternative and Complementary Medicine, 17(3), 213-218.

Sin, N. L., \& Lyubomirsky, S. (2009). Enhancing well-being and alleviating depressive symptoms with positive psychology interventions: A practice-friendly metaanalysis. Journal of Clinical Psychology, 65(5), 467-487.

Singh, N. N., Lancioni, G. E., Manikam, R., Winton, A. S., Singh, A. N., Singh, J., \& Singh, A. D. (2011). A mindfulness-based strategy for self-management of aggressive behavior in adolescents with autism. Research in Autism Spectrum Disorders, 5(3), 1153-1158.

Singh, N. N., Lancioni, G. E., Singh, A. D., Winton, A. S., Singh, A. N., \& Singh, J. (2011). Adolescents with Asperger syndrome can use a mindfulness-based strategy to control their aggressive behavior. Research in Autism Spectrum Disorders, 5(3), 1103-1109.

Spielberger, C. D., Gorsuch, R. L., \& Lushene, R. E. (1970). Manual for the state-trait anxiety inventory. Consulting Psychologists Press.

Tan, L., \& Martin, G. (2012). Taming the adolescent mind: Preliminary report of a mindfulness-based psychological intervention for adolescents with clinical heterogeneous mental health diagnoses. Clinical Child Psychology and Psychiatry, 18(2), 300-312.

U.S. Department of Health and Human Services, and Centers for Disease Control and Prevention (2013). Mental health surveillance among children-United States, 2005-2011. Morbidity and Mortality Weekly Report, 62, 1-35.

Van Dam, N. T., Sheppard, S. C., Forsyth, J. P., \& Earleywine, M. (2011). Self-compassion is a better predictor than mindfulness of symptom severity and quality of life in mixed anxiety and depression. Journal of Anxiety Disorders, 25(1), 123-130.

Walsh, T. M., Stewart, S. H., McLaughlin, E., \& Comeau, N. (2004). Gender differences in childhood anxiety sensitivity index (CASI) dimensions. Journal of Anxiety Disorders, 18(5), 695-706.

Weare, K., \& Nind, M. (2011). Mental health promotion and problem prevention in schools: What does the evidence say? Health Promotion International, 26(Suppl. 1), i29-i69.

Wilkinson, L. (1999). Statistical methods in psychology journals: Guidelines and explanations. American Psychologist, 54(8), 594.

Wood, A. M., \& Joseph, S. (2010). The absence of positive psychological (eudemonic) well-being as a risk factor for depression: A ten year cohort study. Journal of Affective Disorders, 122(3).

World Health Organization (2002). The world health report 2002: Reducing risks, promoting healthy life. World Health Organization.

Zeidan, F., Johnson, S. K., Diamond, B. J., David, Z., \& Goolkasian, P. (2010). Mindfulness meditation improves cognition: Evidence of brief mental training. Consciousness and Cognition, 19(2), 597-605.

Zenner, C., Herrnleben-Kurz, S., \& Walach, H. (2014). Mindfulness-based interventions in schools-A systematic review and meta-analysis. Frontiers in Psychology, 5, 603.

Zoogman, S., Goldberg, S. B., Hoyt, W. T., \& Miller, L. (2015). Mindfulness interventions with youth: A meta-analysis. Mindfulness, 6(2), $290-302$.

Zylowska, L., Ackerman, D. L., Yang, M. H., Futrell, J. L., Horton, N. L., Hale, T. S., \& Smalley, S. L. (2008). Mindfulness meditation training in adults and adolescents with ADHD: A feasibility study. Journal of Attention Disorders, 11, 737-746. 